\section{EXCAVACIONES ARQUEOLÓGICAS EN ANDALUCÍA: 1984-1995}

\author{
ARCHAEOLOGICAL EXCAVATIONS \\ IN ANDALUSIA: 1984-1995
}

\author{
IGNACIO RODRÍGUEZ TEMIÑO (*) \\ SANDRA RODRÍGUEZ \\ DE GUZMÁN SÁNCHEZ (*)
}

\section{RESUMEN}

Este trabajo analiza la evolución de las excavaciones arqueológicas en Andalucía desde la transferencia de competencias del Gobierno del Estado a la Junta de Andalucía. Se presta especial atención a los efectos negativos de la división entre una arqueología de investigación y otra de salvamento; y a cómo el interés en favorecer la primera ha entorpecido el desarrollo conceptual de la segun$\mathrm{da}$, corriendo el riesgo de ser considerada como un mero acto administrativo carente de proyección científica.

\begin{abstract}
This article analyses the evolution of archaeologi-cal excavations in Andalusia since the transfer of responsibilities for Archaeological Heritage management from central Government to the Junta de Andalusia. Special attention is paid to the negative effects of the division between research and salvage archaeology, and to how interest in developing the former has hindered the conceptual development of the latter, thus risking its being considered a mere administrative act, with no scientific projection.
\end{abstract}

Palabras clave: Patrimonio Arqueológico. Gestión. Investigación. Política y Arqueología. Andalucía.

Key words: Archaeological Heritage. Management. Research. Policy and Archaeology. Andalusia.

(*) Dirección General de Bienes Culturales, Junta de Andalucía. C/ Levíes, 27. 41071 Sevilla. Tfno. 95/455 98 60; Fax 95/ 4559865 .

El artículo fue remitido en su versión final el 26-II-1997.

\section{INTRODUCCIÓN}

El presente trabajo tiene un ámbito temporal muy concreto. Se inicia en el momento en que se producen las transferencias de funciones y servicios en materia de patrimonio arqueológico de la Administración central -Ministerio de Cultura-, al Gobierno de la ComunidadAutónoma deAndalucía (Anexo 1, apartado B del R.D. 864/84, de 29 de febrero), y finaliza en la actualidad cuando, agotado un ciclo que coincide con el final del primer cuatrienio del Plan General de Bienes Culturales (PGBBCC) aprobado por el Parlamento de Andalucía en 1989 (Consejería de Cultura, 1993), se están sentando las bases de una nueva etapa de reflexión que bien podría aprovechar, como instrumento de lanzamiento, el II Plan General de Bienes Culturales (1996-1999).

Este período de tiempo ha sido ya objeto de atención por otros autores, que lo han valorado de forma diversa.

A. Ruiz (1989), recogiendo el debate interno de la Comisión Asesora de Arqueología (CAA) presidida por él mismo, fue el primero en sistematizar y definir públicamente una forma diferente de entender la gestión de la arqueología, en un trabajo de carácter teórico y programático. Con los términos «presencias» y «ausencias» elabora una radiografía de la ciencia arqueológica de la segunda mitad del siglo XX en España. Ésta vendría caracterizada por los siguientes componentes: subordinación de la prospección a la excavación, ausencia de un proyecto teórico reflexionado y separación entre trabajo inte- 
lectual (investigación) y trabajo manual (conservación).

En su opinión, se configura lo que podría denominarse genéricamente un modelo andaluz de arqueología a finales de 1984 a partir de tres contingencias: la creación de la CAA y de los equipos técnicos en las delegaciones provinciales de la Consejería de Cultura, junto a la publicación de la orden reguladora de las subvenciones para las actividades arqueológicas. La decidida voluntad de ruptura con el periodo anterior se manifestaría fundamentalmente en las siguientes características que definen el modelo: el cambio de la actuación aislada por el proyecto como instrumento de conocimiento; la incorporación de la conservación al mismo, estableciéndose una interrelación entre conservación e investigación; y, por último, la sustitución de una difusión selectiva por otra, más social.

Resultan muy relevantes para esta reflexión dos riesgos que señala el autor sobre la actividad de gestión del patrimonio arqueológico: el empleo inmoderado de la excavación como único instrumento de intervención, en detrimento de otras medidas de carácter preventivo, y el ser considerada como una actividad de segundo orden con respecto de la investigación.

Por su parte V. Salvatierra (1994), asumiendo la definición del anterior, habla ya de un Modelo Andaluz de Arqueología como algo consolidado y perfectamente definido. Se centra en la historia de sus transformaciones desde su concepción, a la que atribuye cierto origen italiano, en los años $84 / 85$ hasta el momento en que escribe. Esta evolución, para él, fue claramente positiva hasta alcanzar un momento crítico, en 1989, coincidiendo con el cambio de director general de Bienes Culturales. A partir de entonces comienza una inflexión en la andadura del Modelo caracterizada por su «sometimiento al poder político», que lo abocaba necesariamente a un periodo de crisis del que esperaba ver el final con el nuevo equipo surgido de las elecciones autonómicas de 1994.

Su concepción de las actividades arqueológicas en Andalucía como un proceso en adaptación continua y su apreciación sobre la carencia de una teoría de la gestión arqueológica, nos parecen muy acertadas, pero no que haga descansar la comprensión de este proceso en un relato guiado por el aprecio que siente por la labor de unos y el desprecio por la de otros.

Por su parte, M. Acién (1994), que inicialmen- te confiaba en la superación de la etapa precedente a partir de la nueva estructuración conceptual y administrativa de la arqueología en Andalucía, si se solventaban definitivamente determinadas cuestiones relacionadas con la intervención de escuelas-taller en castillos y otras fortificaciones medievales (Acién, 1991), advierte más tarde la insuficiencia del diseño planteado para garantizar por sí mismo su eficacia. Ve el fallo de estos dispositivos en la actitud complaciente con el poder político por parte de arqueólogos reticentes a comprometerse con sus responsabilidades. En la arqueología medieval, ámbito donde se centran la mayor parte de sus reflexiones, la culpa de todo parece tenerla el hecho de resultar ésta molesta por cuanto que, al añadir un campo más a la franja patrimonial, provoca fastidio en el resto de los arqueólogos, especialmente en aquellos con responsabilidades en su conservación.

Su análisis sobre el perjuicio que supone para la intervención arqueológica la separación entre el arqueólogo profesional y el científico (o especialista), así como las consecuencias, en el plano práctico, derivadas de tal división (Acién, 1994: 69), merecen una especial consideración y sobre este tema volveremos más adelante. No obstante, este autor contribuye a tal separación asumiendo sin objeción alguna la existencia de una arqueología de urgencia y otra de investigación, como entidades completamente distintas.

Finalmente, D. Vaquerizo Gil (1994) nos sorprende con una exposición de sus convicciones sobre el porqué del mal estado de la «arqueología fáctica» en España en general, y Andalucía en particular. La responsabilidad de ese estado de cosas recae directamente sobre la influencia ejercida por un cúmulo de factores de variada índole, como son la transferencia «sin orden ni criterio» de todas las competencias en materia de patrimonio histórico de la Administración del Estado a las Comunidades Autónomas; el desarrollo urbanístico de nuestras ciudades; la instauración de un sistema de gobierno basado en la pluralidad y el multipartidismo; la pérdida de calidad en la enseñanza; la falta de definición académica para la figura del arqueólogo; el paro o la improvisación continua en la «arqueología de gestión». A su juicio, la solución pasaría por la gestación de un programa científico de intervención en el patrimonio arqueológico que, convenientemente evaluado por una o más comisiones de expertos, habría de estar dirigido por profesores universi-

T. P., 54, n. ${ }^{\circ} 1,1997$ 
tarios para garantizar su solvencia científica y su puntual difusión extrapeninsular. Sólo así las ciudades andaluzas podrán alcanzar el paradigma que suponen en este terreno Mérida, Tarragona... y, claro está, Roma.

Parece, pues, que mientras algunos caracterizan estos años como el momento de creación y puesta en funcionamiento del denominado Modelo Andaluz de Arqueología, otros han centrado su atención en las deficiencias advertidas en esta etapa. Pero, en general, todos reconocen la existencia de un nuevo enfoque en la gestión del patrimonio arqueológico en Andalucía a partir de 1984.

Admitiendo esto último, en nuestra opinión, no ha existido tal Modelo Andaluz de Arqueología, si por ello debiéramos entender una concepción aglutinadora de toda la actividad arqueológica. Antes bien, la arqueología andaluza en el periodo analizado se ha caracterizado por la radical separación entre una «arqueología de investigación»-desarrollada por las universidades-y una mal denominada «arqueología de gestión» (creemos más apropiado llamarla gestión del patrimonio arqueológico), a cargo de profesionales y de los cuadros técnicos de las administraciones con responsabilidades en la protección y conservación de este patrimonio. Esta división se ha correspondido con desarrollos diferentes entre una y otra y en cierta medida, como procuraremos mostrar en las páginas siguientes, antagónicos.

La idea sobre la que se ha definido el Modelo realmente oculta esa contradicción. El Modelo Andaluz de Arqueología ha sido un producto teórico elaborado con posterioridad para explicar determinadas actuaciones, cuya función era ordenar exclusivamente la investigación arqueológica a partir de 1984. Con el loable propósito de superar lo que había sido ésta en la etapa precedente, se forjaron un conjunto de criterios sobre los que fundamentar la nueva política en esta materia. Estos criterios, salvando el nuevo valor otorgado a los proyectos de investigación, instrumentalizaban conceptos y opiniones cuya aceptación estaba ampliamente generalizada entre las nuevas generaciones de arqueólogos.

En materia de asociación entre excavación y restauración, otra de las reivindicaciones de la nueva etapa, ya existían notables precedentes entre los equipos que trabajaban en Andalucía. El proyecto de conservación y restauración de la muralla de Los Millares ejecutado parcialmente durante los años 1980, 1981 y 1983 no sólo muestra este temprano interés, sino que supone además un hito en este tipo de actuaciones.

Quizás el elemento más destacable $\mathrm{y}$, sin embargo, menos valorado haya sido el importante apoyo político que ha tenido la arqueología en este proceso, manifestado cabalmente no sólo en la generosa dotación económica a estas actividades, como se ha señalado (Salvatierra, 1994: 3 y 4), sino especialmente en la relevancia adquirida por el político en la nueva relación entre los arqueólogos y la Administración de Cultura. Con la Administración autonómica el responsable político deja de estar ausente para incorporarse a este escenario, como una presencia que asume el papel de referente de la actuación administrativa ante la arqueología profesional y académica. Esta percepción justifica no sólo las continuas alusiones, en la bibliografía antes citada, «al político de turno», sino que además haya quienes esperen de los partidos políticos -y no de las administraciones- un modelo de gestión coherente del patrimonio arqueológico (Salvatierra, 1994: 2; Vaquerizo, 1994: 11).

En una Administración incipiente, carente de estructura técnica suficientemente amplia y consolidada laboralmente, este estado de cosas ha facilitado, cuando se ha creído conveniente, la marginación de la voluntad técnica -en ocasiones es preciso reconocer la existencia de una auténtica inhibición voluntaria- en favor de la directriz política. De ello no puede deducirse, sin embargo, la sospecha generalizada de connivencia entre estos técnicos y los políticos responsables de los departamentos en que prestan sus servicios para la sistemática destrucción del patrimonio arqueológico, como cabe interpretar de ciertas lecturas (Acién, 1994: 70).

Así pues, el análisis riguroso de este periodo precisa entrar con profundidad en aspectos sobre los que se ha guardado un cauto silencio o, simplemente, se ha pasado de puntillas, especialmente si queremos desembarazarnos de inútiles cargas, producto de ciertos errores, y optimizar los aciertos habidos.

Esta valoración la efectuaremos primordialmente desde un punto de vista concreto: la evolución en la concepción de la actividad arqueológica, fundamentalmente la excavación, al considerar que este aspecto, crucial en la institucionalización de la gestión del patrimonio arqueológico, está aún mal resuelto y, por tanto, necesitado de atención si se desean superar, en 
esta nueva etapa, las carencias existentes en este terreno en el Plan General vigente.

Comenzaremos analizando la situación heredada por la Junta de Andalucía en materia de investigación arqueológica, ya que muchos de los desajustes actuales hunden sus raíces en los inicios de la propia arqueología en España. Seguidamente, nos centraremos en la estructuración de esas actividades en el seno de la Consejería de Cultura, a partir de 1984, y cómo se asumieron determinadas premisas cuya consolidación ha impedido, en la práctica, el desarrollo de estrategias globales de tutela del patrimonio arqueológico. Igualmente fijaremos nuestra atención en el similar efecto producido por la dicotomía entre gestión e investigación, sustentada, en cierta medida, por la separación entre una arqueología técnica y otra académica.

\section{PRECEDENTES DEL TRASPASO DE COMPETENCIAS EN 1984}

La arqueología heredada por la Comunidad Autónoma andaluza en 1984 se caracterizaba, amén de por los atavismos ya descritos (Ruiz, 1989), por la práctica reducción de su gestión, centralizada para entonces en la Subdirección General de Arqueología del Ministerio de Cultura, a la autorización y libramiento de partidas presupuestarias tanto para las campañas anuales realizadas por las universidades, como para las urgencias cuya responsabilidad recaía fundamentalmente sobre los museos arqueológicos.

La asociación de estos dos conceptos (autorización y financiación) es un punto crucial.

A partir de la conocida como Ley de Excavaciones de 1911, y su desarrollo reglamentario del año siguiente, el Estado se atribuye la prerrogativa de realizar excavaciones arqueológicas en terrenos públicos o privados, previo expediente de expropiación o indemnización en este último caso. Igualmente somete a su previa autorización administrativa la realización de excavaciones por parte de las corporaciones oficiales o los particulares que así lo deseen, corriendo a cargo de los solicitantes las indemnizaciones a que hubiese lugar. Así mismo crea un organismo administrativo para el control de estas actividades: la Junta Superior de Excavaciones y Antigüedades, cuyas funciones son, entre otras, la autorización de excavaciones y la formación y conservación del registro de excavaciones y sus concesiones.
Aunque esta legislación no preveía la financiación de las excavaciones a particulares, desde muy pronto, salvo para el caso de instituciones extranjeras, la práctica totalidad de las mismas fueron financiadas por la Administración, concretamente por la Junta Superior.

De una u otra forma, esta situación se fue generalizando a lo largo de la primera mitad de siglo, llegando a ser lo más natural identificar autorización con financiación. En la Ley del Tesoro Artístico Nacional, de 1933 y, sobre todo, en su Reglamento de aplicación, aprobado mediante Orden de abril de 1936, se recogen en un apartado especial las excavaciones financiadas por el Estado, sujetas a los planes nacionales de excavación, como instrumento de promoción de las mismas, encargándose la Sección Segunda de la Junta Superior del TesoroArtístico de la designación de las personas que hayan de dirigirlas: la extracción académica, universitaria o museística de los directores de las excavaciones abrirá la puerta definitivamente a la consolidación de este proceso.

Esta circunstancia unida al escaso desarrollo en este país de políticas de investigación, incluidas las científicas y tecnológicas, propició el endosamiento de toda la financiación históricoarqueológica a la Administración cultural, desgajándose de los programas de investigación promovidos por otras administraciones del Estado; de forma que, como se ha señalado, ocupaba el mayor volumen de la actividad generada por el Ministerio de Cultura.

Aunque esta vinculación nunca fue objeto de debate, cabe señalar que en los años anteriores a la promulgación de la Ley 16/85 de Patrimonio Histórico Español (LPHE), en el Ministerio de Cultura, las posiciones estaban bastante alejadas del tratamiento que tradicionalmente había tenido la arqueología, al menos desde el punto de vista teórico. Si bien reducido al ámbito de la investigación histórico-arqueológica, en esas fechas se exponen reflexiones sobre la nueva etapa que se está abriendo en España y que debía permitir el desarrollo de una cualificación científica de la investigación arqueológica (Fernández Miranda, 1985). En ellas encontramos buena parte de los mismos fundamentos del arsenal conceptual aducido para armar el Modelo andaluz, inspiración italiana incluida.

La actuación de las delegaciones provinciales del Ministerio de Cultura, carentes en la mayoría de los casos de personal técnico cualificado, era

T. P., 54, n. ${ }^{\circ} 1,1997$ 
nula en este campo, siendo su principal caballo de batalla la protección y conservación de los monumentos y conjuntos históricos. Prueba de ello es que, al menos en Andalucía, los primeros documentos de gestión del patrimonio arqueológico salieran de las diputaciones provinciales (Verdugo y Mendoza, 1983 y Fernández-Baca et alii, 1984) que, además, tutelaban la mayoría de los yacimientos arqueológicos visitables.

Sin embargo, no todas esas aportaciones tuvieron el mismo valor, y si se desea buscar el nacimiento del concepto moderno de gestión aplicado al patrimonio arqueológico, hay que dirigir la atención hacia el Departamento de Arqueología de la Diputación Provincial de Málaga, entre finales de los setenta y comienzos de los ochenta. Efectivamente, creado en 1978 con el fin de ofrecer un estatuto de protección a los yacimientos arqueológicos mediante las figuras de planeamiento urbanístico, evolucionó a principios de la década de los 80 hacia una visión más amplia de la tutela, con unos fundamentos teóricos realmente avanzados para el entorno en que se movía. La filosofía que ordenaba sus actuaciones partía de unos presupuestos previos básicos:

a) Radical separación entre investigación arqueológica y gestión como contenidos competenciales de órdenes administrativos distintos: la Universidad y la Diputación.

b) El concepto global de gestión incluía una amplia panoplia de actuaciones agrupadas en tres apartados: protección (catálogos e inventarios), intervención (exclusivamente de urgencias) y difusión (Fernández-Baca et alii, 1984).

Este modelo tuvo una vida efímera en esa Administración provincial, de hecho sólo se materializó en el I Plan Provincial de Arqueología en 1983, volviendo el Servicio de la Diputación a partir de 1985 hacia su primitiva dimensión (Machuca y Recio, 1984-85). No obstante, el paso de B. Ruiz, responsable del Departamento de Arqueología, a la Dirección General de Bellas Artes de la Consejería de Cultura, supuso el traslado de esta concepción a la Administración autonómica.

\section{LAS ACTIVIDADES ARQUEOLÓGICAS 1984-95: ARQUEOLOGÍA DE URGENCIA VERSUS ARQUEOLOGÍA DE INVESTIGACIÓN}

Las iniciales actuaciones de la Junta de Andalucía consolidaron de hecho dos líneas de inter- vención sobre el patrimonio arqueológico totalmente separadas: la arqueología sistemática y la preventiva y de urgencia. La abrupta separación entre ambas a efecto de objetivos, órganos encargados de su ejecución e instrumentos reguladores, así como los escasos nexos de unión entre sí, ponen en crisis la existencia de una concepción unitaria previa de la política arqueológica a desarrollar en Andalucía, por parte tanto de los responsables de la Consejería de Cultura, como de su órgano asesor en esta materia.

En 1984, ante la urgente necesidad de regionalizar las autorizaciones y financiación de las excavaciones, que venían realizando las universidades, se constituye la CAA dentro de las Comisiones de Bellas Artes como órgano consultivo cuya finalidad era, de acuerdo con la exposición de motivos del Decreto 248/84, de 25 de septiembre, la de asesorar en la defensa, protección y conservación del patrimonio arqueológico. La Orden de 28 de enero de 1985 regla el otorgamiento de autorizaciones para la realización de actividades arqueológicas en Andalucía, estableciéndose en su art. 15 la resolución de las solicitudes por el director general de Bellas Artes (a partir de 1986 de Bienes Culturales), a la vista del preceptivo informe de la CAA que, debido a su solvencia sobre la materia, se incorpora literalmente al texto de la resolución, actuando como motivación de la misma. Por último, la Resolución de 13 de junio de 1985 regula la concesión de subvenciones para la realización de actividades arqueológicas, de las que expresamente se excluyen las obras de consolidación, vallado y otras actuaciones de conservación preventiva, dedicándose exclusivamente a las tareas de excavación y prospección, en sus diversas modalidades. Los objetivos de esta nueva política se fijaron básicamente en el campo de la investigación arqueológica, sin afectar sustancialmente al de la gestión. Consecuentemente con lo anterior, se eligieron especialistas en diversos períodos culturales, del Paleolítico a la Edad Media, como miembros integrantes de la CAA.

Esta relación entre regulación, autorización de actividades sistemáticas, financiación y CAA, será tenida por el eje fundamental del Modelo que, a pesar de su voluntad de cambio, precisaba incorporar determinadas continuidades de la etapa anterior para su funcionamiento. De ellas, la que sin lugar a dudas tuvo mayor importancia en el desarrollo posterior, fue la identificación de 
aprobación de proyecto de investigación con financiación a cargo de la Consejería de Cultura. De forma que, si bien en teoría podrían darse licencia a proyectos sin financiación, en la práctica sólo investigarían quienes a la autorización del proyecto se le sumase una subvención para el mismo.

El interés prestado durante los primeros años a las actividades de investigación, o sistemáticas, provocó la confluencia sobre ellas de la mayor parte de los esfuerzos administrativos, económicos (en 1985 tenían las actividades de urgencia y las sistemáticas presupuestos globales similares) y jurídicos.

La citada Orden de 1985, por ejemplo, no contemplaba la regulación para autorizar actividades de urgencia. De hecho, desde 1984, para la atribución de la dirección de las mismas a los arqueólogos provinciales se recurría a un proceso bastante similar al de las actividades sistemáticas, si bien ya existían en aquel momento determinados requisitos imprescindibles para conseguir la autorización pertinente para cada intervención concreta que, significativamente, no emanaba del director general de Bienes Culturales, sino del delegado provincial, oída la correspondiente Comisión Provincial de Patrimonio Histórico. Esta ausencia en una norma, caracterizada por su afán reglamentador (1), lejos de ser anecdótica, clarifica el orden de prioridades de la Consejería en ese momento.

Así pues, aunque la postura oficial (García León, 1985), hecha poco después del traspaso de competencias, apuntaba la unión indiscriminada de gestión e investigación en cada una de las etapas en que se estructuraba la arqueología en Andalucía: consolidación del soporte administrativo y promoción de proyectos científicos de investigación, tal visión sólo era un espejismo ya que ambas ramas eran entendidas, en la práctica, como compartimentos estanco.

Este aislamiento ha impedido o, al menos, entorpecido el transvase de instrumentos desarrollados por los grupos de investigación con proyectos sistemáticos (fichas de prospección, sistemas de registro de excavaciones, etcétera) a los equipos

(1) Esta orden llega al insólito extremo de exigir un permiso expreso para el estudio de materiales depositados en museos en función de criterios tales como el curriculum del investigador o la memoria de objetivos a corto plazo, en lugar de la mera autorización administrativa del director de la institución, a tenor de las disponibilidades del centro y del efecto de las investigaciones sobre la conservación del material arqueológico, como sucede en los archivos. que trabajaban en el entorno de las delegaciones, en urgencias y emergencias. Y, aún peor, también ha limitado la circulación de la información necesaria para mejorar el ejercicio de la tutela sobre el patrimonio arqueológico, a pesar de estar financiada dicha información con dinero de la propia Consejería, escudándose en una discutible interpretación del derecho a la propiedad intelectual.

Las actuaciones de urgencia no han sido siempre bien acogidas por determinados sectores académicos, que incluso las han atacado, midiéndolas con un rasero bastante más severo que el usado para sus proyectos de investigación. Como se trasluce de algunas de estas invectivas (Pastor y Pachón, 1992), su trasfondo es el miedo a que las urgencias substrajeran buena parte de los recursos económicos destinados por la Consejería a financiar las actividades sistemáticas.

$\mathrm{Si}$ bien en teoría existían relaciones entre la CAA y el conjunto de los arqueólogos provinciales, en la práctica sólo se destinaron a separar aún más ambos bloques. En esa época los miembros de la CAA, y los responsables políticos de la Dirección General, se muestran terriblemente cautos con la autorización de las excavaciones de urgencia para evitar su conversión en sistemáticas encubiertas. A ello contribuía la existencia de una fuerte corriente de opinión favorable a la disociación de la arqueología de urgencia y la arqueología de investigación, en atención quizás a la consideración de aquella como actuaciones esporádicas, de finalidad muy concreta y que, en ningún caso, debían desencadenar campañas de duración prolongada.

Siendo absolutamente cierto que, ante la fácil disponibilidad de medios económicos, algunos arqueólogos provinciales promovieron excavaciones por la vía de urgencia, insalvables desde el punto de vista de la gestión y sólo comprensibles por intereses de investigación personales, no lo es menos que la férrea aplicación de ese dogma ahogó la posibilidad de dar cobertura científica y metodológica a otro tipo de actuaciones de urgencia, como las excavaciones urbanas, cuya continuidad no podía evitarse.

Muestras palmarias de este afán fueron las trabas puestas a los funcionarios de la Consejería de Cultura para impedir que dirigiesen o codirigiesen proyectos de investigación y, especialmente, la enucleación de todo contenido de investigación a las excavaciones de urgencia hecha por la Resolución de 28 de abril de 1988, donde se re-

T. P., 54, n. ${ }^{\circ} 1,1997$ 
coge, en su punto $4^{\circ}$, que la finalidad de las mismas será «evitar la situación de urgencia», con independencia de cualquier otra consideración.

De hecho, la afirmación del Plan General de Bienes Culturales «existen dos trabajos básicos en materia arqueológica que son la arqueología preventiva o de protección y la arqueología de investigación» (Consejería de Cultura, 1993), se ha tomado como la asunción por parte de la Consejería de esta actitud proclive a la drástica división. Evidentemente ayudaba a ello el escaso soporte económico, y de cualquier otro tipo, que tenían los equipos dedicados a urgencias (especialmente urbanas) para desarrollar un programa de investigación, a pesar del enorme interés de las intervenciones llevadas a cabo.

Al hilo de esta última precisión conviene advertir que existe una diferencia importante en esta materia entre la legislación de ámbito nacional (LPHE) y la regional (Ley 1/91 de Patrimonio Histórico de Andalucía -LPHA-).

El tratamiento dispensado por la LPHE -aplicable en Andalucía con carácter supletorio a la LPHA o en los aspectos no tratados por éstaal patrimonio arqueológico es el de un patrimonio especial cuyas actividades están sujetas a la pertinente autorización por parte de la administración competente, que deberá velar por que el desarrollo de los trabajos se ajuste a un «programa detallado y coherente que contenga los requisitos concernientes a la conveniencia, profesionalidad e interés científico» ( $\left.\operatorname{art}^{\circ} 42 \mathrm{LPHE}\right)$. En ningún caso se habla de separación entre actividades de urgencia y de investigación, siquiera a nivel procedimental.

Por su parte la LPHA, recogiendo los precedentes ya analizados, sí hace esta diferenciación, dejándola en el límite mismo de la confusión entre procedimientos y objetivos. En los artículos 52,53 y 54 se establecen los diferentes tipos de actividades arqueológicas que necesitan autorización previa de la Consejería de Cultura, quiénes pueden solicitar tales autorizaciones y, finalmente, las líneas básicas del procedimiento a seguir, previniendo su desarrollo reglamentario. $\mathrm{El} \operatorname{art}^{\circ} 59.1$ introduce una diferencia al permitir a la Consejería autorizar actividades de urgencia mediante un procedimiento simplificado. Pero, además, su punto $2^{\circ}$ señala como finalidad concreta superar la situación que las provoca. Para el legislador andaluz, pues, las actividades de urgencia se diferencian de las otras, fundamental- mente en una limitación de objetivos y no en el procedimiento a seguir, ya que es optativo del órgano autorizante (el art $^{\circ}$ 59.1 LPHA emplea el término "podrá») el establecimiento de un procedimiento abreviado para su aprobación. De ello cabe deducir que no todos los tipos de actividades arqueológicas contempladas en el mencionado $\operatorname{art}^{\circ} 52$ son susceptibles de ser consideradas dentro de la categoría de urgencias, sino exclusivamente aquellas cuya realización sirva para superar una situación de grave pérdida de bienes y elementos integrantes del Patrimonio Arqueológico andaluz.

El Reglamento de Actividades Arqueológicas, aprobado mediante Decreto 32/1993, de 16 de marzo (RAA), al desarrollar cuestiones puramente procedimentales no resuelve esta situación sino que aumenta las trabas burocráticas. El RAA sigue considerando las actividades de urgencia como de «carácter menor» y trámite más aligerado, no siéndoles, en la práctica, de aplicación la mayoría de los contenidos previstos para los proyectos generales de investigación. Aunque se pida la entrega en el plazo de un año de la memoria científica, no se dispone de ninguna medida de ayuda o fomento a esa investigación, con lo que realmente se está limitando su producción.

Sin menoscabo de sus valores y aportaciones, hoy es preciso admitir que tanto la LPHA como el RAA no han sabido apreciar la complejidad de la gestión del patrimonio arqueológico y, el insustituible papel desempeñado en ella por las actividades de urgencia. Olvido que ha pignorado su propia eficacia, al dejar fuera de su capacidad normalizadora aquellas actuaciones más decisivas y habituales en el quehacer diario y, para colmo, consolidando la nefasta división entre una arqueología a la que se reconoce capacidad investigadora y otra que, privada de esa dimensión, sólo interesa en su aspecto procedimental.

Al margen de cómo fuesen contempladas en la normativa, las actuaciones de urgencia ya comenzaron a diversificarse desde 1986 en urgencias programadas, aquellas derivadas de las actuaciones urbanas o en medio rural ya conocidas y, por tanto, susceptibles de programación y emergencias o urgencias no programadas, producidas tras hallazgos casuales o paralizaciones de obras por destrucción de restos arqueológicos (Ibáñez Castro, 1987: 26 y 27). A esta división básica, prácticamente aceptada sin discusión, se añaden otros supuestos como fueron las interven- 
ciones de apoyo a la restauración, que tuvieron su paradigma, en cuanto a financiación y duración, en las excavaciones realizadas en la Cartuja de Santa María de las Cuevas con motivo de la Exposición Universal Sevilla'92 (2).

Pero fue, sin duda, en el campo de la arqueología urbana, uno de los principales caballos de batalla de la gestión del patrimonio arqueológico a partir de 1984, donde la situación era más compleja, debido a que la separación entre urgencia e investigación dejaba un amplio margen de indefinición cuyas consecuencias han sido verdaderamente desastrosas.

Aunque desde 1985 entre las actividades sistemáticas había ciertos proyectos cuyo objeto de estudio se encontraba en medio urbano, la mayoría de ellos centraba su investigación en un periodo concreto o en un monumento, desentendiéndose del conjunto de la ciudad, por lo que no pueden ser considerados como auténticos proyectos de arqueología urbana.

Así, pues, la mayoría de las ciudades se han convertido en una especie de «tierra de nadie» en la que, faltos de un proyecto de investigación que cualificase su metodología y diseñase una estrategia de intervención y objetivos a cubrir, trabajaban diversos profesionales sin vinculación entre sí, haciendo de cada solar un caso concreto sin conexión con el resto de las investigaciones realizadas en la misma ciudad.

Extirpada de su función como instrumento de investigación, la excavación termina siendo entendida como un mero acto administrativo a realizar previo a una construcción, limitando su eficacia al propio hecho de producirse. Estos condicionantes, unidos a la desproporcionada presión ejercida por los agentes implicados en los procesos de sustitución inmobiliaria, precipitaron el surgimiento de una situación donde predominaba la gestión, evaluada en términos de «agilidad» $\mathrm{y}$ «eficiencia», sobre el contenido real de incremento del conocimiento. Esto ha propiciado la aparición de esas «reglas» comentadas por M. Acién (1994), de cuya aplicación se ex-

(2) RAA sí resuelve la situación particular de estas excavaciones de apoyo a la restauración de inmuebles, definiendo un tercer tipo de actividades arqueológicas, denominadas «Actividades Arqueológicas no enmarcadas en Proyectos Generales de Investigación», para recoger, entre otras, estas intervenciones cuya finalidad como base informativa para los proyectos de restauración, les otorgaban unos contenidos de investigación incompatibles, al parecer, con su inicial consideración como actuaciones de urgencia. traía la obligada duración de un mes por excavación, o la inconveniencia de profundizar por debajo de la cota de construcción del proyecto de nueva planta. En muchos casos, la desproporción entre la superficie total de los solares y el área realmente excavada dentro de ellos ha sido tal, que permite albergar dudas muy razonables sobre la verdadera contribución al conocimiento de la ciudad de esas campañas de excavación (Rodríguez Temiño, 1991).

Así pues, aunque la consolidación de la arqueología urbana en las ciudades andaluzas de mayor importancia había sido un logro de la Administración autonómica, ciertamente su producto no viene siendo el esperado aumento de información sobre la estructura urbana y social de los núcleos de población sujetos a estas intervenciones desde hace más de 10 años.

A partir de 1992, en la propia Dirección General de Bienes Culturales, se propugna un cambio de rumbo en la arqueología en general y en la urbana especialmente, argumentando la necesidad de revisar «desfases y desequilibrios en aquellos campos vinculados directa o indirectamente con esta actividad debido, fundamentalmente, a que el afianzamiento y la institucionalización de ciertas bases, inicialmente de marcado carácter instrumental, ha supuesto en la práctica un desarrollo diferencial entre los distintos compartimentos en que se ha dividido el proceso global que comporta la tutela del Patrimonio Arqueológico» (Rodríguez Temiño y Puya García de Leaniz, 1993: 65).

Estas lagunas eran fundamentalmente: a) la ausencia de proyectos de investigación de arqueología urbana, como consecuencia de una minusvaloración de la arqueología de urgencia; b) la inadecuación del marco jurídico otorgado por la figura jurídica de conjunto histórico (art. 15.3 LPHE) para amparar la arqueología urbana, con sus consiguientes efectos en el planeamiento urbanístico; c) el tratamiento fragmentario de la arqueología urbana potenciando, aunque de forma deficitaria, aspectos como la excavación en detrimento de otros como la conservación, la investigación o la protección.

La respuesta de la Dirección General de Bienes Culturales no fue unitaria y adoleció de descoordinación, al no tener la arqueología urbana un reflejo administrativo claro, teniendo cada servicio competencias parciales sobre ese ámbito. Así durante un par de años funcionaron con

T. P., 54, n. ${ }^{\circ} 1,1997$ 
desigual intensidad dos programas: «Programa de Catalogaciones Específicas de Zonas Arqueológicas en Ciudades Actuales» y «Programa de Proyectos de Arqueología Urbana».

El primero, tras el intento fallido de la catalogación específica de la zona arqueológica de Cádiz debido a la oposición municipal, sufrió un considerable estancamiento centrándose exclusivamente en la elaboración de la documentación de la zona arqueológica de Granada y la carta de riesgo de Sevilla. El segundo, con mayor autonomía administrativa, en 1992 y 1993 sacó sendas convocatorias para la presentación de proyectos de arqueología urbana en un conjunto de ciudades, seleccionadas en función de criterios como la preexistencia de proyectos sistemáticos que afectasen a cascos urbanos o la problemática arqueológica y situación del planeamiento en esas ciudades.

A partir de 1994 los dos programas anteriores se unieron, sumándoseles además un tercero relativo al "Sistema de Registro de Excavaciones Arqueológicas" con la intención de vertebrar un "Programa Especial de Arqueología Urbana". Se procuraba que la tutela del patrimonio arqueológico elaborase unos nuevos presupuestos teóricos acordes con el desarrollo de la ciencia arqueológica, asumibles en un plano práctico por aquellos organismos vinculados a su gestión. Se precisaba abrir una nueva etapa que asumiese la experiencia acumulada y proyectase hacia el futuro un programa alternativo, cuyo fin fuese la consolidación de todos aquellos aspectos relacionados con la protección, conservación, investigación y difusión recogidos en el Plan General de Bienes Culturales.

La arqueología urbana debía entenderse como un proceso global de tutela del patrimonio arqueológico y no meramente como un conjunto de excavaciones en medio urbano. Esa filosofía inspiró las directrices de una Comisión de Arqueología Urbana para la redacción de los proyectos de arqueología urbana de las principales ciudades andaluzas (3).

Esta Comisión ha sido la primera en agrupar

(3) Estas directrices, contenidas en sendos documentos distribuidos en las Jornadas de Arqueología Andaluza (Córdoba, 1994) y en una reunión de proyectos de arqueología urbana (Antequera, 1995), están aún inéditas. Los únicos proyectos que han visto la luz han sido el de Jaén (Pérez et alii, 1995) y el de Granada (Moreno, 1995). Estas directrices han tenido eco en determinadas propuestas de gestión del patrimonio arqueológico ( $\mathrm{Ge}-$ rencia Municipal, 1995; Ayuntamiento de Córdoba, 1995). técnicos de la Dirección General y de las delegaciones, junto a profesores universitarios, para la evaluación de este nuevo tipo de proyectos. Su nombramiento ha coincidido con la virtual disolución de la CAA, una vez extinguido el periodo de seis años de los primeros proyectos generales de investigación aprobados, sin que hasta el momento se hayan nombrado los nuevos componentes de la misma.

A lo largo de este proceso la propia CAA ha sufrido un amplio desgaste en la aplicación de la política trazada sobre investigaciones sistemáticas. $\mathrm{Su}$ traducción en un cierto distanciamiento entre ésta y la Dirección General ha sido reflejado por M.Acién (1994: 78) como la transformación de la CAA «de asesora en consultiva», entendiendo que en ese cambio ha perdido capacidad de influir sobre los responsables políticos del centro directivo.

Esta pérdida progresiva de protagonismo de la CAA en el quehacer de la Dirección General de Bienes Culturales no afectó, realmente, al control ejercido sobre los proyectos de investigación sistemática. En este terreno las fisuras en el bloque monolítico que suponían los principios rectores de su actuación aparecen cuando la denegación de autorizaciones para actividades arqueológicas son contestadas bien por la vía legal, bien siguiendo una política de hechos consumados. A través de ellas afloran no sólo las deficiencias del Modelo, sino especialmente el modo en que la disociación entre el criterio político y el académico se vuelve, por vez primera, contra la propia CAA. Un rápido examen de dos casos concretos arrojarán luz sobre estos extremos.

Tras una primera aprobación de intervención en 1985 en la necrópolis de La Joya (Huelva) (Garrido, 1970), la Consejería deniega la autorización en 1986, aludiendo insuficiencia científica del proyecto. Agotada la vía administrativa, el solicitante emprende la contencioso-administrativa, recayendo Sentencia de la Sala de lo Contencioso-Administrativo de Sevilla, de 5/02/90, del Tribunal Superior de Justicia de Andalucía, que obligaba a la Administración a retrotraer el expediente a la fase de motivación. Vuelta a denegar la autorización para las campañas de 1987, 1988, 1989 y 1990, el Tribunal aprecia nuevamente falta de sustanciación en la justificación, amonestando a la Administración por su falta de claridad, y ordenando retrotraer el expediente nuevamente a la fase de argumentación (Sentencia de 28/6/ 93). Por último, ante la inconsistencia de las mo- 
tivaciones expuestas por la Administración para denegar la autorización para 1991, 1992 y 1993, el Tribunal resolvió reconocer el derecho a excavar del interesado (Sentencia de 19/02/95).

En este caso, la contradicción y núcleo del conflicto radica, en nuestra opinión, en la imposibilidad de calificar un proyecto de científicamente insuficiente, sin poner en solfa la credibilidad científica del firmante y, de paso, el propio sistema académico. Por eso la CAA (cuyos miembros proceden del mundo universitario) encargada de elaborar la justificación de las resoluciones del director general en esta materia, se muestra incapaz de asumir el papel que se le había encomendado y no tiene más remedio que recurrir a un subterfugio, ajeno a los planteamientos iniciales, que no convence a los magistrados de la Sala.

Sin embargo, de ello no cabe extraer que todo profesor universitario, al reconocérsele el deber de investigar, tenga adquirido el derecho a excavar (Garrido, 1995: 292). El propio Tribunal en las dos primeras sentencias no accede a otorgar al demandante permiso de excavaciones, entendiendo que, de estar correctamente motivadas, las denegaciones serían perfectamente admisibles. Sólo ante la evidente contradicción de no autorizar un proyecto de excavación en Huelva capital recurriendo a la existencia de otro que, con similares contenidos, tiene como territorio de estudio yacimientos diseminados por media provincia onubense, el Tribunal decide autorizar el proyecto de La Joya. Si en vez de acudir exclusivamente a los contenidos científicos y metodológicos de la investigación arqueológica, la discrecionalidad administrativa de las autorizaciones y denegaciones se centrase más en los efectos que las actuaciones previstas tendrían sobre la conservación del patrimonio arqueológico, la argumentación tocaría terreno más sólido amén de más acorde con las competencias de la Administración tuteladora de los bienes culturales y, por tanto, menos susceptible de ser recurrida por arbitraria. Lógicamente el órgano capacitado para valorar estos condicionantes debería estar compuesto por un espectro profesional más amplio, y ser independiente del juego de intereses académicos.

Por su parte, los reparos de la CAA a las intervenciones anuales del proyecto «Presencia humana y ocupación antrópica en el Pleistoceno Inferior en la región de Orce (Granada)» han sido contestadas, por parte del equipo, mediante la vía política. Para ello se ha instrumentado el respaldo del Ayuntamiento de la localidad (Castellar, 1992) y del Parlamento de Andalucía (4) y, por último, el eco producido en los medios de difusión por la celebración en Orce del Congreso Internacional de Paleontología Humana, en septiembre de 1995 (5), usado como plataforma por el equipo de investigadores para quejarse del trato recibido por la Junta de Andalucía (6).

Los efectos de esta estrategia no se hacen esperar y en la clausura se llega a un acuerdo con el consejero de Cultura para la viabilidad y financiación de las excavaciones en los yacimientos paleontológicos de Orce, responsabilizando a la Comisión Asesora de la situación creada (7). En ningún momento de esta polémica se mencionan siquiera los argumentos esgrimidos durante tantos años por la CAA para denegar las autorizaciones. El presidente del Parlamento de Andalucía en el acto de clausura titula lo acontecido: «J. Gibert ha ganado la batalla de la opinión pública y del Parlamento» (8).

\section{EL CRITERIO TÉCNICO DE LA ADMINISTRACIÓN Y EL DESARROLLO DEL CONCEPTO DE GESTIÓN}

La percepción de que una de las piezas claves del Modelo Andaluz de Arqueología ha sido la articulación al mismo de las tareas propias de gestión, realizadas por los arqueólogos provinciales (Ruiz, 1989) es manifiestamente errónea. En la práctica, se propició desde el inicio un desplazamiento en la elaboración de la voluntad técnica de la Administración de los arqueólo-

(4) En la pasada legislatura el grupo parlamentario Izquierda Unida-Los Verdes presentó una Propuesta no de Ley, para que el Parlamento instase al Consejo de Gobierno la creación de una Comisión formada por representantes de la Consejería de Cultura, el Ayuntamiento de Orce, la Diputación de Granada y el propio equipo, para el desarrollo de la comarca a través de la puesta en valor del yacimiento (Boletín Oficial del Parlamento de Andalucía, 89. Sevilla, 16 de junio de 1995).

(5) Los organizadores del Congreso usaron como "reclamo» periodístico una disputa directa con el yacimiento de Atapuerca reivindicando para Orce el honor de haber entregado los restos del «primer europeo» (Ideal, Granada, 02.09.1995; Tribuna, 04.09.1995; Diario 16. Andalucía, 07.09.1995; Tiempo, 11.09.1995).

(6) Correo de Andalucía, 05.09.1995 y 07.09.1995; Ideal, Granada, 07.09.1995 y Diario 16. Andalucía, 05.07.1995.

(7) Ideal, Granada, 08.09.1995.

(8) Correo de Andalucía, 09.09.1995. 
gos provinciales a la CAA, entendiendo que su criterio estaba mejor cualificado (Salvatierra, 1994: 5).

Esta derivación, fomentada por los responsables de la Consejería de Cultura, acentuó la división entre gestión e investigación, si bien se proponía justamente lo contrario. Aún a riesgo de repetir algunas ideas ya expresadas, nos parece importante revisar la separación entre ambos términos desde la óptica enunciada en este apartado, al haber sido uno de los principales obstáculos para el desarrollo de una teoría de la tutela del patrimonio arqueológico más acorde con el marco disciplinar, social y legislativo en que nos movemos.

La inicial filosofía de la gestión de la Diputación Provincial de Málaga no provenía de los conceptos presentes en la legislación sobre el Patrimonio Histórico-Artístico (que seguía siendo la citada Ley de 1933), sino de la aplicación de la virtualidad protectora que la legislación del suelo confiere a los instrumentos de ordenación del territorio (Machuca y Recio, 1984-85: 217). A tenor de lo publicado del Plan Provincial de Arqueología 1983, esa primera aportación se vio enriquecida con la adaptación de la teoría de la restauración, más cercana a la Carta de Atenas de 1931 que a la del Restauro de 1972 (FernándezBaca, 1984), a los supuestos concretos de los yacimientos y monumentos arqueológicos (Fernández-Baca et alii, 1984).

Ello no tiene nada de insólito, si reconocemos que las técnicas de protección urbanística y la conservación y restauración arquitectónicas han sido las fuentes más valiosas para extraer los conceptos básicos con los que armar una incipiente teoría y práctica de la gestión del patrimonio arqueológico (9).

El impulso heredado de la Diputación malagueña pronto se vio desbordado, en la práctica, ante la necesidad de acometer una serie de actuaciones derivadas del nuevo marco institucional y legislativo (poco después del traspaso de competencias entró en vigor la LPHE), impensables en el horizonte competencial de una administración local.

En su nueva andadura, la Administración autonómica procuró en primer lugar cubrir con técnicos los órganos periféricos -las delegaciones

(9) Otro ejemplo temprano de la extensión de conceptos arquitectónicos a la arqueología se encuentra en los valiosos comentarios de A. Jiménez (1982) a la Carta del Restauro de 1972. provinciales- que soportaron el peso de gestionar las nuevas competencias. En algún caso, como el de Málaga, fue la Diputación la depositaria de estas nuevas funciones, exclusivamente durante 1984, al ser el único organismo público de ámbito provincial con técnicos cualificados.

El esquema organizativo de las delegaciones provinciales de la Consejería de Cultura se llenará de contenido real en 1986, cuando se doten de personal a través del Plan de Actuación Especial en Materia de Bellas Artes (PAEMBA), y se habilite a los arqueólogos provinciales para pedir subvenciones con objeto de poder atender las emergencias y urgencias que surgieran (Resolución de 25 de febrero de 1986, Disposición Adicional $1^{\mathrm{a}}$ ). Ambas medidas supondrán el culmen del proceso en materia de gestión del patrimonio arqueológico.

El desarrollo conceptual de esta etapa fue disparejo. Mientras que en el campo de las actividades sistemáticas, la Comisión Asesora perfilaba un modus operandi en torno a la exigencia de un proyecto de investigación, acorde a los avances teóricos y metodológicos de la disciplina, a los equipos que solicitaban autorización de excavaciones; el quehacer diario, cuyo abanico comprendía desde la protección hasta conferencias en centros docentes, sumía a los arqueólogos provinciales en una espiral de la que era difícil sustraerse para dedicarse a la teorización.

A partir de 1987 comienza un episodio caracterizado por la generalización de un clima de debate, como prolegómenos a la redacción del Plan General de Bienes Culturales, que terminará con su aprobación por el Parlamento de Andalucía en 1989. Esta etapa, especialmente significativa para el marco teórico de la gestión del patrimonio arqueológico, vio su integración (especialmente en la vertiente de bienes inmuebles) como un componente más dentro de la tutela global del patrimonio histórico (10). Ello abrió paso a la incorporación de técnicos de otras especialidades en la reflexión sobre la protección, conservación, restauración y difusión de los bienes de carácter arqueológico así como, a los nuevos aires que, provenientes de Italia, propugnaban la revisión de la construcción

(10) A este respecto, cabe señalar que en la nueva estructura administrativa de la Dirección General de Bienes Culturales, se suprime el antiguo Servicio de Arqueología y Etnología, diluyéndose sus competencias entre los servicios de Protección e Investigación. 
doctrinal sobre los bienes culturales (Perego, 1987). Si bien, el PGBBCC, en su redacción final, sólo acusa la renovación italiana superficialmente. Por otra parte, el Plan de Investigación Arqueológica -dentro del Programa de Investigación del PGBBCC - que resumía los criterios sobre esta materia mantenidos por la Comisión durante esos años, quedaba como un documento de difícil integración en el resto de la estructura del PGBBCC, debido a que sus objetivos seguían centrándose en el estudio de ciertos horizontes culturales y no en los aspectos patrimoniales.

Esta divergencia de criterios cristalizará en 1991 con la promulgación de la LPHA, que contempla en su conjunto una forma de gestión del patrimonio arqueológico, desde su concepción como bienes muebles e inmuebles, bastante más completa que la derivada de su consideración como un patrimonio especial cuyas actividades están sujetas a determinado tipo de autorización.

A comienzos de esta década la Dirección General de Bienes Culturales incorporó nuevos técnicos con objeto de poner en funcionamiento las competencias y el diseño administrativo emanados del PGBBCC. Como resultado de este aporte, ese centro directivo adquirió capacidad técnica para formular nuevos proyectos y programas de actuación. Ello, unido a la centralización de los expedientes económicos de inversión, provocó una descompensación administrativa en detrimento de los órganos periféricos que, hasta entonces, habían llevado de una u otra forma las iniciativas en esos ámbitos.

Esta situación se verá sancionada en la distribución de funciones establecida por el Reglamento de Organización Administrativa del Patrimonio Histórico de Andalucía (ROA), aprobado por Decreto 4/1993, de 26 de enero. En él, el director general se reserva las autorizaciones de proyectos generales de investigación arqueológi$\mathrm{ca}$, las actuaciones fuera de los proyectos generales y las actuaciones de urgencia, sin perjuicio de aquellas competencias que ostenta en materia de protección y conservación de bienes muebles e inmuebles (zonas arqueológicas y zonas de servidumbre arqueológica, artículos 27.5 y 48 LPHA). Las delegaciones provinciales desempeñaban la mera función de información, supervisión, ejecución y propuesta en estas materias hasta la Resolución de 21 de junio de 1995, de la Dirección General de Bienes Culturales, por la que se delegan en los delegados provinciales de la Consejería, determinadas competencias en materia de Patrimonio Histórico.

El esfuerzo del renovado cuadro técnico de la Dirección General de Bienes Culturales en el Servicio de Protección se concentró, fundamentalmente, sobre la sistematización del encajamiento de la arqueología en el planeamiento urbanístico (Rodríguez Temiño, 1992), las fichas de inventario de yacimientos (González-Campos y Fernández, 1996) y, sobre todo, la adecuación al nuevo escenario surgido de la LPHA de los criterios de actuación en arqueología urbana (Rodríguez Temiño y Puya García de Leaniz, 1993). Esta última propuesta dio lugar al "Programa Especial de Arqueología Urbana", cuyos desarrollos fundamentales han sido expuestos más arriba.

Por otra parte, el Instituto Andaluz del Patrimonio Histórico (IAPH), ideado como un programa especial dentro del PGBBCC, se crea mediante Decreto de 16 de mayo, como órgano dependiente de la Dirección General. A través de sus centros de Intervención, Documentación y Formación se ha consolidado durante estos años como pieza clave en la profundización del pensamiento patrimonial en Andalucía. El Boletín Informativo (más tarde Boletín del Instituto Andaluz del Patrimonio Histórico) y la colección de Cuadernos, editados por el IAPH, se han constituido como vehículo de difusión de nuevas experiencias, proyectos, cursos y aportaciones personales sobre temas relacionados con los bienes culturales. Las nuevas directrices del II Plan General de Bienes Culturales, expuestas en las Jornadas celebradas recientemente en Úbeda y Bae$\mathrm{za}$, se han elaborado igualmente en su entorno (Fernández Salinas, 1996).

Para dar una dimensión cuantitativa de la gestión diremos que, en la actualidad, se contabilizan aproximadamente 40 arqueólogos en la Consejería de Cultura entre funcionarios y otro personal con diverso tipo de contrato (incluidos los facultativos que prestan sus servicios en museos). En la última Relación de Puestos de Trabajo (RPT), aprobada en 1995, se contemplan 72 puestos para arqueólogos, pero el número actual no supone una «colmatación» proporcional de la lista contemplada en la RPT, sino que responde a una sucesión de coyunturas cuyo final ha favorecido más la dotación de plazas en servicios centrales, en detrimento de los órganos territoriales. Esta actitud ha sido coherente con el sentido aglutinador de competencias observable en el ROA.

T. P., 54, n. ${ }^{\circ} 1,1997$ 


\section{CONCLUSIONES}

Para concluir quisieramos hacer tres reflexiones puntuales a modo de consecuencia de lo dicho.

En primer lugar, parece obvio admitir el cambio habido en el escenario desde 1984 hasta ahora. La investigación no puede ser considerada por más tiempo como un elemento paralelo a la gestión. Ha de integrarse como una faceta más dentro de un programa conjunto de tutela. Es más, junto a la difusión habría de ocupar la cabecera de la actuación patrimonial, si se desea que ésta cumpla la doble función de instrumento de conocimiento histórico-arqueológico y de gestión (Molina et alii, 1996). Parece ya obsoleto crear comisiones para especialistas en horizontes culturales, cuyos derroteros estén desgajados del resto del proceso administrativo sobre los bienes culturales. De igual manera habría que considerar si la Administración de Cultura debe seguir financiando proyectos de investigación histórica, o bien debe invertir sus recursos económicos en proteger, conservar, difundir y poner en valor el conocimiento adquirido, y los bienes involucrados, como fruto del proyecto. Ello sin renunciar, no obstante, a sus competencias de autorización de las actuaciones de cuyo resultado se derive riesgo evidente para la conservación del patrimonio arqueológico. A tenor de lo anterior, es necesario adecuar aquellos instrumentos normativos como el RAA- que se muestran poco aptos para la gestión de los bienes culturales.

En segundo lugar, la irrupción de los responsables políticos no habría de suscitar mayor recelo sino fuese porque han incorporado, al quehacer diario, un nuevo marco de referencias bastante alejado de la realidad cotidiana. Esto ha provocado una polarización del proceso de gestión y va camino de abrir una fractura entre las decisiones y sus fundamentos técnicos.

En tercer lugar, al menos en Andalucía, se percibe un cambio de actitud del hombre de la calle hacia estos temas. Hace diez o doce años, en general la mayoría de la opinión pública se alineaba con los arqueólogos en la batalla por la conservación del patrimonio arqueológico. Hoy día, como refleja un exhaustivo informe sobre la arqueología urbana en Córdoba (11), la sociedad percibe nuestra actuación como algo caótico, carente de

(11) Diario Córdoba, 13.01.1996. criterios y sin finalidad aparente. Esta falta de sensibilidad hacia el entorno ha sido, sin lugar a duda, nuestra principal carencia. Recibimos gratuitamente un importante caudal de afecto y apoyo social que hemos dilapidado al imponer incomodidades y renuncias, sin explicar el porqué o, al menos, compensar por ello.

Superar esta situación requiere plantearse la integración de la voluntad administrativa y política en programas diseñados para alcanzar objetivos concretos, que contemplen el proceso completo de tutela, suturando teoría y realidad de forma que se facilite al ciudadano la fruición de su pasado.

\section{BIBLIOGRAFÍA}

Acién Almansa, M. (1994): «Política y Arqueología ¿Dependencia?». Arqueología y Territorio Medieval, 1: 67-74.

Ayuntamiento de CóRdoba (1995): Córdoba: Patrimonio de la Humanidad. Excmo. Ayuntamiento. Córdoba.

Castellar, L. (1992): «Presentación». En J. Gibert (coord.). Presencia humana en el Pleistoceno inferior de Granada y Murcia: 13-14. Museo de Prehistoria J. Gibert (Ayuntamiento de Orce). Granada.

Consejería de Cultura (1993): Plan General de Bienes Culturales. Junta de Andalucía. Sevilla.

FERnÁNDEZ-BaCa CASARES, R. (1984): «La intervención en Arqueología clásica: el teatro romano de Acinipo (Ronda)». Actas del II Congreso Andaluz de Estudios Clásicos (Antequera, 1984): 269-275. Sociedad Española de Estudios Clásicos. Málaga.

Fernández-Baca Casares, R.; Corrales Aguilar, M. y García León, M. (1984): «Una alternativa a la defensa del Patrimonio Arqueológico andaluz: la experiencia del Plan Provincial de Arqueología 1983». Actas del II Congreso Andaluz de Estudios Clásicos (Antequera, 1984): 263-268. Sociedad Española de Estudios Clásicos. Málaga.

FERnÁNDEZ-Miranda, M. (1985): «Modelo arqueológico y patrimonio histórico». Análisis e Investigaciones Culturales, 24: 27-36.

FERnÁNDEZ SAlinas, V. (1996): Bases para una Carta sobre Patrimonio y Desarrollo en Andalucía. Instituto Andaluz del Patrimonio Histórico. Sevilla.

GARCíA LEÓN, M. (1985): «Introducción: la arqueología andaluza durante 1984-85. Antecedentes, panorámica actual y perspectivas». Anuario Arqueológico de Andalucía. 1985/I: 7-9. Consejería de Cultura. Sevilla.

GARRIDo RoIz, J.P. (1970): Excavaciones en la Necrópolis de La Joya, Huelva ( $1^{a}$ y $2^{a}$ campañas). Excava-

T. P., 54, n. $^{\circ} 1,1997$ 
ciones Arqueológicas en España, 71. Ministerio de Educación y Ciencia. Madrid.

- (1995): «Comentarios a una sentencia de la Sala de lo Contencioso Administrativo del Tribunal Superior de Justicia de Andalucía en materia de excavaciones arqueológicas». Actas del XXII Congreso Nacional de Arqueología (Vigo, 1993): 291-292. Vigo.

Gerencia Municipal de Urbanismo (1995): Plan Especial de Protección del Conjunto Histórico de Sevilla. Excmo. Ayuntamiento. Sevilla.

González-Campos Baeza, Y. y Fernández Cacho, S. (1996). «La Base de Datos: Zonas arqueológicas en Andalucía». Boletín del Instituto Andaluz del Patrimonio Histórico, 16: 112-118. Sevilla.

IBÁÑEZ CASTRo, A. (1987): «Memoria de gestión de las actividades arqueológicas de la Provincia de Córdoba, 1986». Anuario Arqueológico de Andalucía. 1987/I: 26-32. Consejería de Cultura. Sevilla.

Jiménez MARTín, A. (1982): Carta del Restauro'72. Colegio Oficial de Arquitectos. Sevilla.

Machuca Santa-Cruz, L. y Recio Ruiz, A. (1984-85): «Memoria de gestión del Plan Provincial de Arqueología 1985». Mainake, VI-VII: 217-228.

Molina González, F.; Rodríguez Temiño, I.; Contreras Cortés, F.; Esquivel Guerrero, J.A. y PeÑa Ruano, J. (1996): «Un Sistema de Información Arqueológica para Andalucía». I Jornadas de Catalogación del Patrimonio Histórico (Sevilla, 1995): 76-85. Instituto Andaluz del Patrimonio Histórico. Sevilla.

Moreno Onorato, A. (1995): «The Urban Archaeological Project in Grenade». First Annual Meeting. Abstracts (Santiago de Compostela, 1995): 30. European Association of Archaeologists. Santiago de Compostela.
Pastor Muñoz, M. y Pachón Romero, J.A. (1992): «Reflexiones sobre las quintas Jornadas de Arqueología Andaluza». Revista de Arqueología, 132: 54-55.

Perego, F. (coord.) (1987): Memorabilia: il futuro della memoria. Editori Laterza. Roma-Bari.

Pérez Martínez, M. C.; Hornos Mata, F. y Alcázar HERNÁNDEZ, E.M. (1995): «El Proyecto 'Arqueología Urbana 93': Un instrumento de conocimiento e intervención para la ciudad de Jaén». Arqueología y Territorio Medieval, 2: 155-176.

Rodríguez TEMIÑo, I. (1991): «Algunas cuestiones sobre el urbanismo de Hispalis en época republicana». $\mathrm{Ha}$ bis, 22: 157-175.

- (1992): «Arqueología urbana y planeamiento». Revista d'Arqueologia de Ponent, 2: 111-123.

Rodríguez Temiño, I. y Puya García de Leániz, M. (1993): «Zonas arqueológicas en ciudades actuales». En D. Oliva (coord.): Casa-palacio de Miguel de Mañara. Consejería de Cultura y Medio Ambiente. Sevilla: 65-85.

Ruiz RodríGuez, A. (1989): «De las arqueologías a la Arqueología». En 1978-1988 Andalucía: Diez años de Cultura. Consejería de Cultura. Sevilla: 11-17.

Salvatierra Cuenca, V. (1994): «Historia y desarrollo del Modelo Andaluz de Arqueología». Trabajos de Prehistoria, 51(1): 1-13.

VAQUERIZO GIL, D. (1994): «Arqueología de Gestión/Arqueología de Investigación: ¿Disyuntiva o complemento?». Cassandra, 2: 9-21.

Verdugo Santos y Mendoza Castells, F. (1983): «Gestión y planeamiento en el conjunto arqueológico de Itálica». Primeras Jornadas de Arqueología en las ciudades actuales (Zaragoza, 1983): 83-96. Excmo. Ayuntamiento. Zaragoza. 